\title{
O PATRIMÔNIO CULTURAL AFRO-BRASILEIRO: SÃO JOSÉ, UM ESTUDO DE CASO
}

The african-brazilian cultural heritage:

São José, a case study

\author{
JOANA CÉlIa dos PaSSOS, TÂNIA TOMÁZIA DO \\ NASCIMENTO E JOÃO CARLOS NOGUEIRA
}

http://dx.doi.org/10.1590/S0103-21862016000100011

\footnotetext{
Joana Célia dos Passos é doutora em Educação pela UFSC, professora do Centro de Ciências da Educação da UFSC e pesquisadora em educação e relações étnico-raciais (passos.jc@gmail.com).

Tânia Tomázia do Nascimento é doutora em Quaternário Materiais e Culturas pela Universidade de Trás-os-Montes e Alto Douro (UTAD), Portugal, e pesquisadora do Núcleo de Estudos Negros (taniatomazia@yahoo.com.br).

João Carlos Nogueira é doutorando em Quaternário Materiais e Culturas na Universidade de Trás-os-Montes e Alto Douro (UTAD), Portugal, e pesquisador do Núcleo de Estudos Negros (jcnogueira13@gmail.com).

Artigo recebido em 27 de janeiro e aprovado para publicação em 21 de março de 2016.
} 


\title{
RESUMO
}

0 presente texto apresenta os resultados de um estudo de caso que teve como objetivo analisar como e 0 que tem sido considerado pelo poder público bem patrimonial da população afro-brasileira em um município catarinense. Analisa também o que pensam os moradores(as) sobre os bens patrimoniais da população. Foram utilizados como procedimentos: análise documental, aplicação de questionário e entrevistas. Como resultado, constatou-se que os referenciais de patrimônio cultural simbolicamente atuantes ainda são os tradicionais patrimônios "a pedra e cal". Nessa perspectiva, o patrimônio cultural associado à população afro-brasileira fica excluído, em grande medida, porque popularmente não é visto como patrimônio cultural.

PalaVRas-CHAVE: patrimônio cultural afro-brasileiro; relações raciais.

\begin{abstract}
This paper presents the results of a case study that analyses how and what has been pointed by the authorities as the cultural heritage of the African-Brazilian population in a town of the state of Santa Catarina. It also analyses what the local population thinks about the question. To carry out this investigation we have employed: analysis of documents, questionnaires and interviews. As a result we found that the symbolically active cultural heritage of reference still consists of the traditional heritage as churches, forts, museums, etc. In this perspective the cultural heritage associated with the African-Brazilian population is largely excluded because in general it is not regarded as cultural heritage.
\end{abstract}

KeYwords: African-Brazilian cultural heritage; racial relations

\section{RÉSUMÉ}

Cet article présente les résultats d'une étude destinée à analyser ce qui est considéré (et comment) par les authorités comme héritage de la population afro-brésilienne dans une ville de l'État de Santa Catarina. II analyse aussi ce que pensent les habitants sur la question. Pour ce faire, nous avons eu recours à l'analyse de documents, à des questionnaires et à des interviews. À la fin, nous avons constaté que les références d'héritage culturel symboliquement actives sont encore celles traditionnelles. Dans cette perspective, I'héritage culturel associé à la population afro-brésilienne reste exclu en grande partie, parce qu'il n'est pas vu par la population comme héritage culturel.

Mots-CLÉS: héritage culturel afro-brésilien; relations interraciales. 


\section{INTRODUÇÃO}

$\mathrm{O}$

modelo de política cultural estabelecido no Brasil ainda tende a legitimar apenas uma pequena parcela da população como produtora de memória, história e cultura. Grande parte desse processo de exclusão está associada ao projeto de nação com base em teorias raciais, produzido pela elite brasileira entre o século XIX e os anos iniciais do século XX, e que tinha como perspectiva um país branco, "civilizado" e europeu.

Para Nogueira e Nascimento (2012: 70), a elite

Vivia a contradição de negar mais da metade da população, negra, ex-escrava e indígena, queria industrializar-se, mas vivia a barbárie de uma escravidão tardia, um capitalismo dependente, baseado numa economia agroexportadora e enredada no debate sobre raça, para excluir e negar o caráter positivo da miscigenação na identidade brasileira.

Portanto, ao definir os bens patrimoniais coletivos a serem preservados, a elite brasileira acaba por reproduzir uma visão colonizadora, monocultural e eurocêntrica, negando as histórias, as culturas, as memórias e as identidades das populações negras e indígenas. Ao reconhecer os bens patrimoniais de apenas um único grupo social como representantes da memória coletiva de todos os brasileiros, o Estado assume o ideal de branqueamento e reforça o sistema de dominação já constituído pela condição socioeconômica de negros e indígenas.

Essa concepção impacta ainda hoje, daí por que discutir a importância do patrimônio cultural afro-brasileiro na atualidade. Implica ainda desafiar as estruturas que mantêm o mito da democracia racial e o racismo institucional no âmbito do Estado e, portanto, na gestão das políticas públicas.

É nesse contexto que se insere o presente texto, que apresenta resultados de um estudo de caso ${ }^{1}$ realizado no município de São José, em Santa Catarina, no período 2010-2011 e que teve como objetivo compreender como e o que tem sido considerado pelo poder público como bem patrimonial da população afro-brasileira e o que pensam os(as) moradores(as) sobre os bens patrimoniais dessa população. Para o alcance dos objetivos propostos foram realizados os seguintes procedimentos metodológicos: a) pesquisa bibliográfica secundária sobre o patrimônio e história do município de São José; b) consulta a fontes documentais primárias localizadas no 
Arquivo Histórico, na Biblioteca e no Museu Histórico Municipal de São José; c) aplicação de questionários e realização de entrevistas com moradores(as) e gestores(as) municipais, visando a coletar suas percepções sobre os bens patrimoniais da população afro-brasileira no município. Além de aspectos como nome, sexo, cor/raça, tempo de residência no município, as questões que orientaram as entrevistas foram: o que você entende por Patrimônio Histórico Cultural? 0 que, em sua opinião, é Patrimônio Histórico Cultural de São José? O que você caracteriza como Patrimônio Histórico Cultural da população afro-brasileira? 0 que você caracteriza como Patrimônio Histórico Cultural da população afro-brasileira em São José? Quais são as manifestações culturais afro-brasileiras em São José? Você considera que o Boi-de-Mamão também é uma manifestação cultural afro-brasileira? Por quê? No caso dos gestores, acrescentou-se: enquanto gestor(a) público, qual sua maior facilidade para lidar com os bens patrimoniais? E quais as maiores dificuldades? Você apontaria alguma área, ou ações que poderiam contribuir com o município na preservação de seus bens culturais? Que outros locais (áreas, pessoas, instituições) você indicaria para pesquisar sobre o Patrimônio Histórico Cultural de São José?

\section{BENS PATRIMONIAIS AFRO-BRASILEIROS: ESPAÇOS DE PERTENCIMENTO}

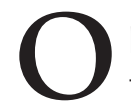

patrimônio afro-brasileiro, como conceito e definição, remete a um "conjunto de bens físicos e simbólicos que nos individualiza" (Rufino,1997: 2), mas que também nos atribui um sentido coletivo. 0 autor exemplifica:

O negro não foi quem nos deu a língua, derivação do sermo vulgaris ibérico, nem o molde inicial de nossa fala, a língua geral, mas foi ele que ensinou o proto-brasileiro a falar português - tanto o proto das minas quanto o da selva, o do litoral quanto o do sertão... de forma que no plano linguístico é difícil separar o patrimônio afro-brasileiro.

No entanto, os bens patrimoniais materiais e imateriais na cultura negra são visíveis. Ainda segundo Rufino (1997:3), " a etnografia do boi no Norte e Nordeste remonta ao século XVIII, a matriz mitológica estava na África e na Europa, mas a sua difusão pelo Brasil é uma proeza do negro-brasileiro: onde houve escravidão, houve boi" . Os bens materiais e imateriais da população afro-brasileira têm portanto suas especificidades e individualidades, mas conceitualmente se confundem com o patrimônio e a cultura nacional.

0 patrimônio cultural pode ser definido como um conjunto de bens - materiais e imateriais - herdados, ou como a propriedade cultural e o modo de vida de diferentes grupos que formam uma sociedade. Subdivide-se, essencialmente, em três grandes áreas: uma correlacionada 
ao ambiente natural, outra associada ao saber ou produção intelectual e outra decorrente da produção intelectual, um bem material concreto produzido pela ação humana. Mas, se ponderarmos que uma sociedade é composta por um grupo de pessoas que compartilham entre si e mantêm suas especificidades, rapidamente concluiremos que diferentes interesses, propósitos, valores e identidades atuam nos critérios de definição e seleção do que é patrimônio cultural.

Ao historicizar o conceito de patrimônio, Funari \& Pelegrini (2006) atentam para isto e advertem para a concepção individual e coletiva do termo. No espaço privado, o patrimônio é concebido como um bem que transmitimos aos nossos herdeiros e que pode ser de ordem material, como acima citado, ou imaterial, como posturas emocionais, práticas religiosas, gestos dos afazeres, etc. Já no espaço coletivo, pela diversidade de gostos, necessidades e interesses, a decisão sobre o que é patrimônio passa a ser algo externo, dependendo da análise alheia como parâmetro de definição. Desta forma, os autores supracitados afirmam que a coletividade tem diferentes interesses, que estão sempre em mutação. Assim, a concepção de patrimônio é algo dinâmico e em processo dialético de desconstrução e construção.

No Brasil as discussões acerca da política de gestão e de preservação patrimonial iniciaram-se por volta da década de 1920, coincidindo com o advento do movimento Modernista, e confluíram em 1936 com um projeto de lei elaborado pelo escritor Mario de Andrade, que alavancou um processo que se perpetua em menor grau até hoje, no qual artistas e arquitetos tomaram a dianteira no processo de consolidação das primeiras iniciativas de proteção do patrimônio nacional. 0 resultado do quadro delineado foi uma clivagem dos bens patrimoniais elencados para proteção e preservação, numa visão tradicional, em que os órgãos competentes, através de seu corpo técnico, atuavam na seleção dos bens, em sua maioria imóveis, casas senhoriais, igrejas e grandes monumentos.

Tal perspectiva, com o alargamento das discussões sobre a temática, bem como do campo de atuação na área patrimonial, mostrou-se ineficiente e recebeu críticas profundas por seu caráter vertical, em que os bens representativos da elite governante foram os eleitos para proteção. E mesmo assim a uma proteção falha, já que os órgãos oficiais não conseguiam ser eficientes nos seus projetos de preservação atuando sozinhos, e que a maior parte da população - neste caso, negra - não encontrava naqueles monumentos significados simbólicos ou valor efetivo de identificação cultural que justificassem seu envolvimento no processo de proteção e preservação.

Atribuiu-se essa falta de engajamento popular a uma lacuna de valor de referência, seja pelo não acesso, seja pelo acesso comprometido a informações, e, em consequência, a uma desvalorização identitária alimentada pela máquina pública, que foi tachada de elitista e excludente. Associando-se aos impactos de modernizações advindas do crescimento econômico, esta seria a maior responsável pela desvalorização e destruição dos bens culturais no Brasil. 


\section{Patrimônio Cultural no MUnicípio de SÃo JOSÉ (SC): MEMÓRIA E SACRALIZAÇÃO}

\section{L}

ocalizado na região centro-leste do estado de Santa Catarina, o município de São José faz parte da Região Metropolitana da Grande Florianópolis. Embora seu povoamento seja atrelado aos idos de 1750 (Piazza e Hübner, 2003; Farias, 1999) com a chegada de 182 casais açorianos que vieram povoar o litoral catarinense, o certo é que muito antes já existiam os indígenas, que povoavam amplamente a região. Informes estatísticos de 1797 apontam que a "Freguesia de São José era composta de 389 fogos (casas habitadas), com população total de 2.079 habitantes, incluindo os escravos, que eram em número de 412, e já existiam escravos libertos, no total de 14" (Gerlach e Machado, 2007:17).

No início do século XIX, por volta de 1840, São José contava com uma população total de aproximadamente 10.419 habitantes, dos quais 2.225 , ou 21,3\%, eram homens e mulheres que estavam na condição de escravizados. Essa população era composta por 1.315 homens solteiros; 909 mulheres solteiras; 36 homens casados; 34 mulheres casadas e três viúvos(as) (Farias, 1999).

De acordo com Gerlach e Machado (2007), em 1853 a população negra existente no município de São José criou a Irmandade do Rosário, composta por pretos livres e cativos. Em 1866, portanto 22 anos antes da Abolição da Escravatura, a população negra no município diminuiu sua representatividade em aproximadamente 4\%, passando a representar $16,2 \%$ do total de habitantes (Farias, 1999). Pesquisas mais recentes, principalmente as inauguradas a partir dos anos 60 e 70 do século XX, indicam tendências distintas quanto à diminuição da população negra nesse período. De acordo com Cardoso e lanni (1960), e Maria (1995), a presença da população negra no Brasil Meridional, nos centros mais dinâmicos da nossa economia, como Florianópolis, São José, Lages, Joinville, Itajaí e Criciúma, girava em torno de um terço da população total. Outro aspecto está relacionado ao Censo de 1872, período em que o processo de miscigenação foi captado pelas amostras quantitativas, revelando os impactos da intensa política de "branqueamento" desencadeada pelo Estado e as elites brasileiras. Nas várias colônias que formavam o município de São José, a presença de homens e mulheres escravizados e livres era representativa. A Colônia Militar Santa Tereza chegou a ser formada por 56,8\% de população negra. Entre esta, 3,8\% eram escravizados (Farias, 1999).

Fato relevante na historiografia contemporânea são as mudanças de paradigmas, em que a história social passou a dedicar especial "reconhecimento" aos sujeitos na construção dos destinos das sociedades e seus territórios. Essas mudanças são relevantes para compreender o papel das populações em condições de escravidão e seus protagonismos nos processos 
de libertação. Nesse turno se valoriza a memória e a contribuição inestimável já consagrada da população negra na formação da cultura e da identidade brasileiras. Nessa perspectiva, a influência da cultura negra no município e região de São José é marcada, primeiro, pela sua presença, desconstruindo assim no imaginário social a fixa ideia de "ausência" nas estruturas que formam o patrimônio material e imaterial da cidade e da região.

Em dados concretos, a população negra em São José apresentou certa estabilidade demográfica ao longo dos séculos XIX e XX, o mesmo sendo percebido neste início do século $X X I$, sempre girando em torno de $17 \%$ a $20 \%$ da população total. Atualmente, ela é de cerca de 40 mil habitantes (IBGE, 2010). Essa presença ativa da população negra no desenvolvimento da cultura josefense está fortemente marcada na pesca, na cerâmica, no Boi de Mamão, ${ }^{2}$ nas religiosidades de matriz africana, no Cacumbi $^{3}$ e em outras manifestações culturais cultivadas na medida em que são discutidas como bens patrimoniais. Confirma-se, assim, que a participação da comunidade na definição dos bens reconhecidos sujeitos a tombamentos e 0 processo continuado de educação e formação patrimonial são decisivos para o reconhecimento e pertencimento dos bens patrimoniais da cultura afro-brasileira.

Nacionalmente, um dos aspectos mais relevantes que marcam as investigações contemporâneas sobre a população afro-brasileira são os territórios negros, compreendidos como espaços de resistência e ressignificação cultural, tais como os quilombos, os clubes sociais negros, as irmandades e as igrejas por elas construídas e mantidas, os terreiros de candomblé, as vilas operárias, a formação dos times de futebol no início do século XX, as escolas de samba e outros territórios que seguramente revelam novas dimensões da vida e obra da cultura afro-brasileira e afro-catarinense.

Diante do apresentado, pergunta-se: o que é caracterizado como bem patrimonial da população negra no município de São José? Para responder a essa pergunta, é preciso compreender como o patrimônio cultural tem sido tratado pelo poder público. Uma leitura mais atenta da legislação ${ }^{4}$ entre os anos de 1995 e 2006 permite observar que, embora se reconheça as mudanças apresentadas ao longo dos anos, a política pública voltada para o patrimônio cultural se insere numa perspectiva conservadora. Ainda que sejam pautados os bens de natureza material e imaterial como constituintes da concepção de patrimônio histórico e cultural, grande parte dos dispositivos legais versa exclusivamente sobre os processos de tombamento, o que permite a centralização das ações institucionais do município em torno dos bens patrimoniais de valor arquitetônico. ${ }^{5}$ A valorização patrimonial é louvável em qualquer de suas esferas. Aqui, chama-se a atenção para não se incorrer no risco de reconhecimento exclusivo do que foi chamado de "patrimônio a pedra e cal", onde apenas casarões, igrejas, 
solares ou qualquer bem de valor arquitetônico excepcional são considerados, em detrimento de outros bens patrimoniais.

Essa abordagem explicita a percepção de que os bens de excepcionalidades foram interpretados como bens pertencentes a uma elite brasileira, "representada" pela opulência de seus casarios e órgãos institucionais (como igrejas e fortes militares). Isso exclui a maior parte da população brasileira desse processo de reconhecimento, já que grande parte da população não possui ligações afetivas e identitárias com esses bens preservados.

Figura 1: Lista de imóveis tombados no município de São José

\begin{tabular}{|c|c|c|}
\hline Decreto & Nome & Data de Construção \\
\hline Decreto no $18.691 / 2005$. & Casarão do Clube $1^{\circ}$ de Junho & Construído no último quarto do século XIX \\
\hline Decreto no $18.692 / 2005$. & Sobrado da Municipalidade & Construído nos finais do século XIX \\
\hline Decreto no $18.693 / 2005$. & Igreja de Nosso Senhor do Bonfim & Construída entre 1851 e 1852 \\
\hline Decreto no $18.694 / 2005$. & Beco da Carioca & Construído em 1840 \\
\hline Decreto no $18.695 / 2005$. & Casa da Câmara e Cadeia & Inaugurada em 1859 \\
\hline Decreto no 18.696/2005. & Casarão da Família Moreira & Século XIX \\
\hline Decreto no $18.697 / 2005$. & Casarão da Família Gerlach & $\begin{array}{l}\text { Construído entre as décadas de } 40 \text { e } 50 \\
\text { do século XIX }\end{array}$ \\
\hline Decreto no $18.698 / 2005$. & $\begin{array}{l}\text { Igreja de Nossa Senhora de Fátima } \\
\text { e Santa Filomena }\end{array}$ & Construída no ano de 1879 \\
\hline Decreto no $18.699 / 2005$. & $\begin{array}{l}\text { Conjunto de casario (formado por } \\
\text { seis imóveis) }\end{array}$ & $\begin{array}{l}\text { Construído ao longo do século XIX e } \\
\text { início do XX }\end{array}$ \\
\hline Decreto no $18.700 / 2005$. & $\begin{array}{l}\text { Escola de Oleiros Joaquim Antônio } \\
\text { de Medeiros }\end{array}$ & Construída no início do século XX \\
\hline Decreto no $18.701 / 2005$. & $\begin{array}{l}\text { Igreja e Cemitério da Irmandade de } \\
\text { Nosso Senhor Bom Jesus dos Passos }\end{array}$ & $\begin{array}{l}\text { A Irmandade obteve Licença Imperial para } \\
\text { erigir uma capela no ano de } 1854\end{array}$ \\
\hline Decreto no 18.702/2005. & Casa de Comércio da Família Petry & Construída no ano de 1909 \\
\hline Decreto no $18.703 / 2005$. & Píer do Rio Maruim & Inaugurado em 1858 \\
\hline Decreto no $18.704 / 2005$. & Casarão da Família Kowalski & $\begin{array}{l}\text { Casa construída pelo Sr. José João } \\
\text { Kowalski em } 1922\end{array}$ \\
\hline Decreto no $18.705 / 2005$. & $\begin{array}{l}\text { Entreposto Comercial da Praia } \\
\text { Comprida }\end{array}$ & Casarão construído no século XIX \\
\hline Decreto no $18.706 / 2005$. & Theatro Municipal Adolpho Mello & Inaugurado em 1856 \\
\hline Decreto no $18.707 / 2005$. & Usina do Sertão do Maruim & Construída em 1910 \\
\hline $\begin{array}{l}\text { Decreto Estadual no } 2.989 \\
\text { de } 25 \text { de junho de } 1998 .\end{array}$ & Igreja Matriz de São José & $\begin{array}{l}\text { Acredita-se que por volta de } 1833 \text { já se } \\
\text { encontrava construída }\end{array}$ \\
\hline $\begin{array}{l}\text { Decreto Estadual no } 26.608 \\
\text { de } 15 \text { de julho de } 1986 .\end{array}$ & Solar do Ferreira de Mello & Início do século XIX \\
\hline
\end{tabular}

Fonte: Construído a partir da Cartilha do Patrimônio de São José - SC: normas e diretrizes e informações disponíveis no site da Fundação de Cultura do Município. 
Com a ampliação do conceito de patrimônio cultural e, consequentemente, de suas áreas de atuação, novas perspectivas são pautadas, a partir de uma visão de que os diversos grupos sociais devem ser contemplados e os diversos tipos de bens devem ser abarcados. No município de São José, a importância de uma nova postura ${ }^{6}$ perante a gestão patrimonial é importante, visto que os diversos bens observados até o momento do estudo estavam "desprotegidos". Os aspectos relacionados aos bens imateriais, como o saber fazer dos oleiros ou a Festa do Divino Espírito Santo, tão divulgados no município, recentemente foram assumidos como patrimônio.

Algumas ações desenvolvidas pelo Arquivo Histórico Municipal de São José já são direcionadas ao registro, valorização e divulgação dos bens patrimoniais do município. Entre elas, podem ser citadas: a) a revista Memórias da terra firme, produzida pelo Arquivo Histórico e dedicada à divulgação de pesquisas, relatos, entrevistas, ou qualquer produção intelectual relacionada às temáticas de cunho histórico de interesse do município; b) o banco de história oral: desde 2009 são registrados, através da gravação de entrevistas, os relatos dos moradores mais antigos do município; as entrevistas são transcritas e disponibilizadas para consulta; c) as exposições, em que documentações sob a guarda do município são divulgadas; cabe destacar a Exposição Negras Memórias, lançada em 2007, formada por 18 banners do Fundo Coletoria, Série Escravos, em que documentos relacionados aos escravizados do município são utilizados como instrumento de divulgação do arquivo, mostrando a realidade de São José no século passado.

Entretanto, essas iniciativas caracterizam-se como ações pontuais. Nem sempre dispõem de respaldo legislativo ou de incentivos (financeiros, recursos humanos, ou planos regulares de realização) que garantam sua efetividade diante das demandas apresentadas pelo município. Diante disso, afirma-se que um modelo de gestão patrimonial, para fazer jus à ideia de política pública, precisa considerar a diversidade patrimonial, em que as diversas naturezas de bens (materiais e imateriais) e os diversos grupos de referências estejam representados.

\section{A VALORIZAÇÃO E A VISIBILIDADE DO PATRIMÔNIO CULTURAL AFRO-BRASILEIRO COMO ATRIBUIÇÃO DOS AGENTES PÚBLICOS}

P ara que fossem alcançados os objetivos propostos pelo estudo foram aplicados 25 questionários a moradores(as) e realizadas dez entrevistas com gestores(as) das pastas vinculadas à educação e à cultura. Quanto ao perfil dos moradores de São José que responderam ao questionário, o maior número eram mulheres, na faixa etária entre 24 e 53 anos, 
enquanto os homens tinham entre 24 e 52 anos. A maior parte (15) se autodeclarou negro(a). Alguns se declaram brancos(as) (8), uma pessoa se autodeclarou parda e uma pessoa não se autodeclarou.

Quando questionados sobre o que entendiam por patrimônio cultural, 46\% dos entrevistados apontaram para uma percepção do patrimônio como um conjunto de bens materiais e imateriais de um grupo. Já $17 \%$ apontaram o patrimônio cultural como um conjunto de bens materiais de uma população. E 37\% deram respostas imprecisas sobre o que entendiam como patrimônio cultural.

Com isso, conclui-se que demonstram compreensão das dimensões materiais e imateriais do patrimônio cultural. Nenhum(a) dos(as) que responderam definiu patrimônio cultural apenas pelo seu viés imaterial. Ao serem questionados(as) sobre o que entendiam sobre patrimônio cultural em sua cidade, $75 \%$ indicaram bens patrimoniais de natureza material e imaterial, enquanto 25\% apontaram apenas aspectos do patrimônio material.

Percebe-se, então, que a maior parte dos josefenses que responderam aos questionários vê seu patrimônio cultural por um viés material e imaterial. Contudo, na prática, quando questionados sobre o que definiam como patrimônio cultural do município de São José, classificaram com maior intensidade os bens de viés material como símbolos de pertencimento da cidade. Neste caso, foi possível identificar dois grupos de bens: a) bens materiais de valor arquitetônico: igrejas, Bica da Carioca, casarios, teatro, Praça 11, ${ }^{7}$ museu, olarias, praças, monumentos, casas de comércio antigas; b) bens de caráter imaterial associados a formas de expressões, saberes, fazeres e celebrações: Cacumbi, Festa do Divino, Boi de Mamão, o saber fazer cerâmica, Pão por Deus, ${ }^{8}$ pessoas e suas histórias, manifestações religiosas.

Ao serem questionados sobre o que consideravam patrimônio cultural da população afro-brasileira em São José, dois grupos de bens foram delimitados: bens materiais de valor arquitetônico, o monumento da abolição, a Bica da Carioca, a Igreja Nosso Senhor do Bonfim, o Praça 11, os casarios e os clubes negros; e bens de caráter imaterial associados a formas de expressões, saberes, fazeres e celebrações: samba, capoeira, Cacumbi, carnaval, culinária, oralidade, Boi de Mamão, documentos, dança e religiosidade.

Observou-se que o bem patrimonial citado com maior destaque foi a Carioca, também conhecida como Beco da Carioca ou Bica da Carioca, com 17 menções. Construída em 1840, a Bica é uma referência por ter sido um espaço de trabalho e sociabilidade da população afro-brasileira no município, já que as famosas "lavadeiras" que trabalhavam na Bica eram negras.

0 outro referencial associado à população afro-brasileira no município é o monumento da Abolição da Escravidão, localizado na Praça Hercílio Luz, no centro histórico do 
município. No monumento, consta uma placa com a data de 1988, ano de reinauguração da praça. Mas não existe menção de que o monumento tenha sido construído nesse momento. Da mesma forma, não existe indicação de quem o projetou ou construiu, ou o motivo de sua construção. Outro monumento chama a atenção no centro histórico de São José. Localizado na Praça Arnaldo Souza, em frente à Praça Hercílio Luz, é popularmente conhecido como monumento do Imigrante. De acordo com o roteiro do projeto "Redescobrindo São José", o monumento foi construído em homenagem aos 250 anos de imigração açoriana no município, em 2000, tendo sido projetado e executado pelo artista plástico josefense Plínio Verani Júnior. Ainda de acordo com o roteiro, o monumento "é repleto de símbolos que evidenciam a forte presença da cultura açoriana". Neste caso, o atrativo é o monumento, ao invés da praça. Existe uma placa no monumento, alusiva à 3a Festa Açoriana ocorrida no município em 2002, com informações sobre os troncos familiares oriundos dos Açores para o município de São José.

Novamente coloca-se a questão do que se caracteriza como patrimônio cultural coletivo (Funari, 2006; Delgado, 1999), e também a necessidade de se tratar equitativamente os bens patrimoniais associados a todos os grupos sociais que formam o município, já que é 0 poder público municipal quem define como, o quê, quando e por que alguns bens são mais divulgados e valorizados que outros.

A religiosidade, juntamente com a capoeira e o Cacumbi, ambos com 13 menções, foram também identificados como patrimônio cultural afro-brasileiro. A culinária teve 12 menções, e o samba, 10. Chama a atenção o fato de o Cacumbi ser um dos referenciais com um dos maiores índices de menções pelos josefenses associado à população afro-brasileira, pois já não faz parte dos costumes na região, ainda que esteja presente na memória coletiva.

Esse exemplo é importante para avaliar a máxima "conhecer para preservar", pois, mesmo não fazendo parte da realidade atual do município, uma manifestação cultural realizada outrora é identificada como um bem de referência da população afro-brasileira, muito em consequência da educação patrimonial desenvolvida no município. Isso se dá através de várias ações institucionais, como por exemplo a divulgação da imagem e da história do capitão Pedro Leite como referencial da cultura negra no município; o fato de haver uma rua com o nome "Pedro Leite"; o troféu "Pedro Leite", que na semana da Consciência Negra homenageia pessoas comprometidas com a promoção da igualdade racial no município de São José. Ou se dá também através de ações do movimento social negro local, que protagoniza atividades referentes à cultura afro-brasileira e à resistência.

Isso leva à reflexão sobre o enfoque proposto por Horta, Grunberg e Monteiro (1999:6), segundo o qual através do patrimônio cultural é possível provocar o indivíduo a 
"fazer a leitura do mundo que o rodeia, levando-o à compreensão do universo sociocultural e da trajetória histórico-temporal em que está inserido", favorecendo assim o "reforço da autoestima dos indivíduos e comunidades e a valorização da cultura brasileira, compreendida como múltipla e plural".

O outro bem associado à população afro-brasileira no município de São José é a Igreja Nosso Senhor do Bonfim. De acordo com a Cartilha do Patrimônio produzida pelo município, "a capela do Nosso Senhor do Bonfim está localizada no alto da Rua do Bonfim, [tendo sido] construída entre os anos 1851 e 1852, com a ajuda de moradores de São José e da persistência do pároco da cidade, Padre Macário César de Alexandria". Ainda conforme a cartilha, o pároco encomendou uma cópia da imagem do Senhor do Bonfim diretamente da Bahia, de onde era natural. Tal ato deu origem à Procissão do Senhor do Bonfim, ainda realizada no município. Conforme as informações orais, a relação da população afro-brasileira com a igreja Nosso Senhor do Bonfim dá-se pelo fato de outrora ter sido essa a igreja frequentada pelos negros na região.

Chama a atenção o fato de o Cacumbi ser indicado como bem patrimonial da população afro-brasileira no Brasil e pouco mencionado como bem da população afro-brasileira no município. Não foi possível detectar, a partir do presente diagnóstico, as reais motivações para tal acontecimento, mas, a título de hipótese, pode-se apontar a falta de ligação emocional e identitária que os entrevistados possuem com a dança. Mesmo reconhecendo o Cacumbi como uma representação cultural afro-brasileira, poucos tiveram envolvimento, participaram, viram, ficando o reconhecimento no plano informativo, distante da realidade dos entrevistados.

Dois entrevistados mencionaram os casarios como patrimônio da população afro-brasileira em São José. A ligação com esses espaços decorre do reconhecimento de que foram os negros que os construíram. Por fim, houve uma menção aos clubes negros como patrimônio cultural afro-brasileiro em São José. Conforme Escobar (2010: 57-58),

A origem dos clubes sociais negros é anterior à abolição da escravatura, em 1888. Eles surgiram como um contraponto à ordem social vigente, além de constituírem-se num local de sociabilidade e de lazer para a população negra, que era impedida de frequentar os tradicionais "clubes sociais brancos". Além disso, tinham como objetivo angariar fundos para o pagamento da liberdade dos trabalhadores negros escravizados, auxiliar nas despesas com funeral e na educação de seus associados, atuando de forma incisiva na luta contra a escravidão e a discriminação racial. Podemos citar o Floresta Aurora de Porto Alegre como o clube social negro mais antigo do país em atividade, fundado em 1872. 
Sabe-se que outrora houve clubes sociais negros no município de São José. Entretanto, não foram encontrados registros documentais sobre eles. Mas nas entrevistas há menções a clubes que funcionavam até a década de 90, chamados pelos entrevistados de "Jamaica da Grande Florianópolis".

Quanto aos bens de natureza imaterial, a religiosidade e o samba aparecem em destaque. Chama a atenção, entre os bens imateriais, a menção a "documentos". O que está associado, no município de São José, à divulgação realizada, através do Arquivo Público, da exposição "Negras Memórias", onde documentações referentes aos negros no município são expostas junto à população.

Para o presente estudo, na busca por informações e fontes primárias foram realizadas visitas e aplicaram-se questionários no Museu Histórico Municipal de São José, Biblioteca Pública Municipal de São José e Arquivo Histórico Municipal de São José. Das três instituições, apenas o arquivo possui documentação específica sobre a população afro-brasileira no município. De acordo com informações coletadas a partir do questionário, o arquivo público dispõe especificamente de dois grupos de documentos onde existem informações sobre a população afro-brasileira:

- Fundo Coletoria, Série Escravos - composto por uma série de cartas, documentos de contabilidade, controle de pagamentos de impostos, etc., contém informações sobre declarações de compra e venda, falecimento, liberdade concedida e subsídios relacionados às "lides burocráticas" dos proprietários de homens e mulheres escravizados.

- Fundo Prefeitura Municipal, Série Gabinete do Prefeito, Subsérie Documentos Recibos - Ofícios - possui informações datadas de 1936, em que diversos ofícios, pedidos, entre outros, são encaminhados ao gabinete do prefeito e fazem referências específicas a demandas e ações das populações afro-brasileiras no município. Informações sobre terreiros, pedidos de ajuda para festas religiosas, etc., podem ser localizados nessa documentação.

A documentação do Fundo Coletoria, Série Escravos, encontra-se higienizada, organizada e acondicionada, e aproximadamente $10 \%$ estão digitalizados, conforme se pode observar no site do arquivo, ${ }^{9}$ onde é possível visualizar alguns desses documentos.

Já a documentação disponível no Fundo Prefeitura Municipal, Série Gabinete do Prefeito, Subsérie Documentos, está higienizada e organizada até 1996, encontrando-se em 
processo de andamento a organização, o acondicionamento e a construção de um banco de dados com digitalização das informações.

Diante do questionamento "Quais são as manifestações culturais afro-brasileiras em sua cidade, nas seguintes categorias: música, religião, alimentação, outros?", foram obtidos os seguintes resultados: as religiões de matriz africana foram as mais mencionadas, seguidas pela culinária e pelo samba.

Chama-se a atenção para a inclusão do "samba do Praça 11", que é referenciado por alguns entrevistados como o "quilombo moderno" ou "quilombo urbano" do município. Localizado em um prédio tombado, o Praça 11 é um bar-restaurante que mantém firme a tradição de promover sambistas da região e realizar shows com sambistas de renome nacional. Caracteriza-se como um reduto do samba no município, mas também um espaço de sociabilidade que congrega a população afro-brasileira em São José. Embora esteja aberto a todos os grupos, é percebido pelos(as) moradores(as) como um espaço cultural e gastronômico da população afro-brasileira no município.

\section{MAS O QUE DIZEM OS GESTORES PÚBLICOS DO MUNICÍPIO DE SÃO JOSÉ SOBRE O PATRIMÔNIO AFRO-BRASILEIRO?}

$\mathrm{F}$ oram entrevistados(as) dez funcionários(as) da prefeitura de São José cuja função possuísse alguma correlação com as questões culturais no município. Especialmente, pessoas em cargos de chefia, em secretarias, fundações e departamentos. 0 maior número de entrevistados era de homens que exerciam o cargo de gestor havia em média um ano. Desses, 30\% se autodeclararam negros e $40 \%$ brancos.

Os(As) gestores(as) percebiam o patrimônio cultural como um conjunto de bens relacionados às esferas materiais e imateriais do seu município. E apontaram como principais dificuldades de atuação junto ao setor cultural no município as seguintes questões:

- a ausência de um plano de cultura para o município. A Fundação de Cultura do município, fundada por lei, possui um organograma interno e caminha para a construção de um plano municipal de cultura;

- a dificuldade de apoio financeiro para as ações e projetos relacionados à cultura. Por ser uma Fundação de Cultura, a autonomia e a prioridade na destinação das verbas acabam comprometidas, o que dificulta as ações nas áreas culturais;

- a não continuidade dos projetos, seja devido à falta de recursos financeiros, seja pela rotatividade na gestão dos cargos (a maior parte dos entrevistados estava em seus 
cargos havia em média um ano). Como nem sempre os projetos possuem continuidade, os resultados são prejudicados. Essa interrupção mostra a fragilidade e a ausência de uma política pública de cultura;

- a falta de instrumentos institucionais que assegurem a continuidade de projetos e garantam o apoio financeiro. 0 que está intimamente ligado ao fato de não existir um plano municipal de cultura no município.

Quando questionados(as) sobre o que entendiam como patrimônio cultural do município de São José, os entrevistados apontaram: as festas religiosas e manifestações populares, como a Procissão do Senhor dos Passos, a Festa do Divino, o Boi de Mamão, o pau de fita, o terno de reis, grupos de corais e os oleiros, além dos bens de natureza arquitetônica tombados pelo município. Em relação ao patrimônio cultural da população afro-brasileira, apontaram o samba - para um dos entrevistados "o samba é a alegria do negro, a simplicidade na maneira de olhar a vida", já que "o samba no pé que eles têm é uma característica da raça"-; a capoeira; as religiões de matriz africana, especialmente a Umbanda e o Candomblé, citando-se os bairros de Bela Vista e Procasa como áreas de intensa concentração de terreiros; e as influências culinárias, como a feijoada.

\section{CONSIDERAÇÕES FINAIS}

partir das informações disponíveis nos questionários e nas entrevistas, apontam-se as
seguintes conclusões.

Demonstrou-se que existe um descompasso entre o que é conceituado e o que é apropriado enquanto patrimônio cultural. Se na "esfera teórica" o patrimônio cultural é definido como um conjunto de bens materiais e imateriais de um grupo, "na prática", quando incitados a nomear os bens patrimoniais, a maior parte dos entrevistados possui como referencial os bens materiais, e mais especificamente as edificações arquitetônicas.

Há certo distanciamento entre o declarado e o vivido. Logo, constata-se que os referenciais de patrimônio cultural, simbolicamente atuantes, ainda são os tradicionais patrimônios "a pedra e cal". Essa situação é reforçada, no caso de São José, pela legislação vigente no município, já que leis de regulamentação específica sobre os bens patrimoniais de natureza imaterial começam a ser observadas.

Como já mencionado, qualquer forma de preservação cultural é salutar. Entretanto, as ações de preservação e valorização patrimoniais desenvolvidas no município de São José ainda se centram nos bens patrimoniais de natureza material. Ações como o "Banco de História Oral", desenvolvida pelo arquivo, são exceção, juntamente com a Festa do Divino. 
Duas questões centrais observadas no estudo são preocupantes: primeiro, a maior parte dos bens materiais associados aos afro-brasileiros faz parte do rol do patrimônio cultural de natureza imaterial; segundo, esse conjunto de bens associados aos afro-brasileiros não "é visto como patrimônio cultural".

No total, quando se questionou o que era entendido como patrimônio cultural da população afro-brasileira no Brasil, a maior parte das menções refere-se aos bens culturais de caráter imaterial, associados a formas de expressão, saberes, fazeres e celebrações. Quatro menções foram feitas aos bens de natureza material e seis menções a lugares ou paisagens culturais.

Entretanto, esse universo de bens em grande medida é excluído do que é caracterizado como patrimônio cultural de forma global e em grande parte do patrimônio do município. O patrimônio cultural é visto, conforme afirmou um dos entrevistados, como "construções antigas, que resistiram ao tempo, ou que representam algum marco histórico, como igrejas, palácios, fortes, praças, etc."

Logo, por essa perspectiva, o patrimônio cultural associado à população afro-brasileira fica excluído em grande parte, porque popularmente não é espontaneamente visto como patrimônio cultural. Caso não fossem feitas perguntas específicas sobre o patrimônio cultural afro-brasileiro, onde ficaria representado o patrimônio de 52\% da população brasileira?

Na prática, o patrimônio a pedra e cal em ação ainda atua no que foi denominado por Pierre Bourdieu como "capital cultural", ${ }^{10}$ que ocorre quando estruturas simbólicas institucionalizam um "capital cultural" configurado como sendo de poucos, ou de apenas parte uma população (Nogueira e Catani, 1998).

Conforme Nogueira e Nascimento (2012), tal realidade na prática justificou a construção de um cabedal ideal a ser valorizado, e favoreceu o uso do patrimônio cultural como instrumento de preponderância de uma elite dominante, de origem europeia, sobre a esmagadora maioria da população brasileira, formada por afro-brasileiros e povos indígenas.

Questiona-se, então, como é assegurada a salvaguarda desse patrimônio afro-brasileiro de viés imaterial em um município onde não existem legislação e práticas para identificar, inventariar e registrar os bens culturais dessa natureza.

Em decorrência disso, chegou-se a outra constatação. Quando questionados sobre o que entendiam como bem patrimonial da população afro-brasileira em sua cidade, grande parte dos entrevistados apontou referenciais que em grande medida foram excluídos do universo atribuído ao patrimônio cultural de maneira geral e ao patrimônio cultural atribuído à população afro-brasileira. 0 que leva a questionar o efeito cascata que apresenta a situação. É como se houvesse diversos níveis de exclusões. Tal situação só será contornada quando um 
debate amplo sobre os lugares de pertencimento e os lugares atribuídos às populações afro-brasileiras também chegar à esfera patrimonial. E ações concretas de educação patrimonial, tal como proposto por Nogueira e Nascimento (2012), forem realizadas em "sua dimensão social abrangente", possibilitando o uso dos bens patrimoniais como instrumentos potenciais de mudanças de mentalidades e valores sociais. Conforme os autores citados:

Neste sentido, os bens patrimoniais podem ser vistos como produto de um processo cultural cujo reconhecimento, consciência e valorização, quando imbuído em uma esfera de representatividade histórica, pode ser utilizado como vetor de transformação, fortalecimento identitário, estimulador de memórias e espaços de pertencimentos (Nogueira e Nascimento, 2012:79)

Em outra instância, observa-se que os entrevistados possuem referenciais de viés material e local associados às populações afro-brasileiras, como a Carioca, o monumento da Abolição da Escravidão em São José, os clubes negros, entre outros. E que o exercício de reconhecimento, valorização, preservação e as atividades de educação patrimonial em torno desses referenciais são essenciais para a inserção e valorização da população afro-brasileira como parte integrante da população global.

Diante isso, o monumento da Abolição da Escravatura e a Bica da Carioca em São José podem ser divulgados, registrados e considerados espaços de pertencimento e de encontro com a memória negra de São José. É necessário orientar um projeto de revitalização cultural dos monumentos elencados como bens patrimoniais da população negra do município, seja através de ações de uso efetivo da Carioca, seja através da coleta de dados sobre o monumento da Abolição da Escravatura, vistos pelos josefenses como bens associados à população afro-brasileira no município.

Por outro lado, é urgente que ações de pesquisa, registro e retorno social de seus resultados sejam efetivadas com as "fontes de informações" disponíveis sobre as populações afro-brasileiras, tal como é feito com as outras parcelas da população. A título de exemplificação, trabalhos monográficos com os dados existentes no "Fundo Coletoria, Série Escravos" e no "Fundo Prefeitura Municipal, Série Gabinete do Prefeito, Subsérie Documentos Recibos Ofícios" estão por ser realizados, da mesma forma que a busca de informações sobre os clubes negros e ações da Irmandade do Rosário.

Em outra seara, é preciso combater as imagens distorcidas e as informações tendenciosas que foram divulgadas outrora como verdades, tais como as afirmações do historiador Álvaro Tolentino de Souza (1939), que, ao se referir às bandas de músicas que existiam em São José, afirmou: 
Contemporaneamente, três bandas de música disputavam a primazia na divina arte de Euterpe. Havia, na sede da cidade, a Perseverança Artística, e na Praia Comprida, duas outras: a Recreio Josephense e a Quebra Quilos. Esta, banda de músicos medíocres, era constituída de mulatos e pretos libertos, sob a direção de Adão Mafra, creoulo troncudo e sem pendores artísticos. (Álvaro Tolentino de Souza, 1939, apud Gerlach e Machado, 2007:233).

O tempo histórico pode desconstruir as distorções outrora tidas como verdades, as imagens rarefeitas do patrimônio e da memória. Mas a dignidade humana tem o seu próprio tempo, sua perseverança para juntar os cacos dos bens materiais e imateriais esquecidos, porém nunca perdidos indefinidamente. 0 protagonismo do patrimônio e da cultura afro-brasileira está em olhar o passado, construindo o presente e o futuro nos seus tempos.

\section{NotAS}

1 Este estudo integra um projeto mais amplo e foi em parte financiado pela Brazil Foundation e pela Embaixada dos Estados Unidos da América no Brasil. As opiniões, resultados das pesquisas e conclusões ou recomendações aqui expressas são do(s) autor(es) e não refletem necessariamente as do Departamento de Estado dos Estados Unidos da América.

2 Manifestação popular realizada no litoral catarinense envolvendo música, teatro, cantorias, personagens humanos e animais, que tem como enredo a morte e ressurreição de um boi.

3 Dança outrora praticada no município de São José, atualmente o Cacumbi já não faz parte dos costumes do município. Entretanto, o referencial ainda é latente na memória coletiva. 0 Cacumbi em São José tem como maior referencial o capitão Pedro Leite, um oficial de justiça, negro, conhecido no município por ser exímio dançador.

4 Lei Ordinária Municipal no 1605/1985; Lei Ordinária Municipal № 3752/2001; Lei Ordinária Municipal no $4429 / 2006$.

5 De acordo com as informações apresentadas pelo Serviço de Proteção do Patrimônio Cultural e Natural (SERPAC), o município de São José possui 19 imóveis tombados, 17 protegidos por lei municipal e dois protegidos por lei estadual. Observa-se que apenas dois têm como referência a população negra: a Igreja de Nosso Senhor do Bonfim e o Beco ou Bica da Carioca.

6 Conforme informações da Fundação de Turismo e Cultura, uma nova lei, onde bens materiais e imateriais serão contemplados, foi enviada à Procuradoria do Município, encontrando-se em fase de análise.

7 Bar restaurante, localizado em um prédio tombado, o Praça 11 é considerado um reduto do samba.

8 Mensagem em forma de quadrinhas rimadas, poesias, escritas em pequenos papéis coloridos e enfeitados contendo declarações de amor, pedidos de namoro e/ou casamento, etc. O Pão por Deus chegou ao Brasil pelos açorianos.

9 Disponivel em: http://ctpmsj.sc.gov.br/arquivo/negras.html. 
10 Bourdieu utiliza o termo "capital cultural" para explicar a desigualdade do desempenho escolar entre alunos oriundos de realidades sociais diferenciadas, uma vez que alunos oriundos de classes sociais favorecidas possuem em seu cotidiano um rol de experiências e assimilações, ou capital cultural (estruturas simbólicas), que facilita o aprendizado, uma vez que a escola acaba por valorizar, em maior grau, o conjunto de informações "institucionalizadas", facilmente acessíveis e reconhecidas pela classe dominante.

\section{REFERÊNCIAS BIBLIOGRÁFICAS}

CARDOSO, Fernando Henrique; IANNI, Otávio. Cor e mobilidade em Florianópolis: aspectos das relações entre negros e brancos numa comunidade do Brasil meridional. São Paulo: CEN, 1960.

DELGADO, Antonio Limón. Patrimonio ¿De quién? In: Patrimonio etnológico: nuevas perspectivas de estudio. Consejeria de Cultura Junta de Andalucía, 1999.

ESCOBAR, Giane Vargas. Clubes sociais negros: lugares de memória e resistência negra, patrimônio e potencial. Santa Maria: UFSM, Mestrado, 2010.

FARIAS, Vilson Francisco. São José 250 anos: natureza, história, cultura. São José, 1999.

FUNARI, Pedro Paulo; PELEGRINI, Sandra. C. Patrimônio histórico e cultural. Rio de Janeiro: Jorge Zahar Editor, 2006.

GERLACH, Gilberto; MACHADO, Osni. São José da Terra Firme. São José, 2007.

HORTA, Maria de Lourdes P.; GRUNBERG, Evelina; MONTEIRO, Adriane Q. Guia básico de educação patrimonial. Brasília: IPHAN, Museu Imperial, 1999.

IBGE. Censo Demográfico, 2010. Disponível em www.ibge.gov.br. Acesso em 10/03/2013.

MARIA, Maria das Graças. Memória subterrânea: construção das representações de identidade do negro em Florianópolis. Esboços. Florianópolis, v. 2, n.2, 1995.

MEMÓRIAS DA TERRA FIRME. Revista do Arquivo Histórico Municipal de São José, 1a ed., ano 1, 2010.

NOGUEIRA, João Carlos; NASCIMENTO, Tânia Tomázia. Patrimônio cultural e cultura afro-brasileira: conflitos e mediações. In: e (orgs.). Patrimônio cultural, territórios e identidades. Florianópolis: Atilénde, 2012.

NOGUEIRA, Maria Alice; CATANI, Afrânio (orgs.). Pierre Bourdieu. Escritos em Educação. Petrópolis: Vozes, 1998.

PIAZZA, Walter F.; HÜBNER, Laura Machado. Santa Catarina: história da gente. 6a ed., Florianópolis: Lunardelli, 2003.

PREFEITURA MUNICIPAL DE SÃO JOSÉ. Cartilha do Patrimônio São José: normas e diretrizes. SERPPAC, 2011. Projeto Redescobrindo São José, 2012.

. Lei Ordinária Municipal № 1605/1985.

Lei Ordinária Municipal ㄲo 3752/2001.

Lei Ordinária Municipal № 4429/2006. 


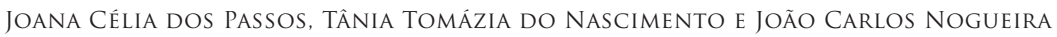

RUFINO, Joel. Culturas negras: civilização brasileira. Revista do Patrimônio Histórico e Artístico Nacional. Rio de Janeiro, IPHAN/MinC, 1997. Disponível em: http://www.palmares.gov.br/sites/000/2/download/04\%20 a\%2009.pdf. Acesso em 12/01/2016. 